\title{
EE
}

PAPER - OPEN ACCESS

\section{Kajian Perancangan Area Tepi Air Dalam Mendukung Desa Nainggolan Sebagai Tujuan Wisata}

\author{
Author $\quad$ : Friza Kinanti Rambe dan Benny O.Y Marpaung \\ DOI $\quad: 10.32734 /$ ee.v3i1.869 \\ Electronic ISSN $\quad: 2654-704 X$ \\ Print ISSN : :2654-7031
}

Volume 3 Issue 1 - 2020 TALENTA Conference Series: Energy \& Engineering (EE)

This work is licensed under a Creative Commons Attribution-NoDerivatives 4.0 International License.

Published under licence by TALENTA Publisher, Universitas Sumatera Utara 
tolentinth hion TALENTA Conference Series

Available online at https://talentaconfseries.usu.ac.id/ee

\title{
Kajian Perancangan Area Tepi Air Dalam Mendukung Desa Nainggolan Sebagai Tujuan Wisata
}

\section{Study Design of a Waterside Area in Support of Nainggolan Village as a Tourist DestinOation}

\author{
Friza Kinanti Rambe ${ }^{1}$, Benny O.Y Marpaung ${ }^{2}$ \\ ${ }^{1,2}$ Program Studi Teknik Arsitektur, Fakultas Teknik, Universitas Sumatera Utara, Jalan Perpustakaan Gedung J7 Kampus USU, Medan, 20155, \\ Indonesia \\ ${ }^{1}$ rambefriza@gmail.com, ²beny.marpaung@usu.ac.id
}

\begin{abstract}
Abstrak
Desa Nainggolan ialah salah satu desa yang terletak di Pulau Samosir, Provinsi Sumatera Utara. Keberadaan Pulau Samosir sebagai salah satu objek wisata di Provinsi Sumatera Utara menjadikan seluruh area dari pulau ini memiliki potensi untuk dalam pengembangan pariwisata. Kondisi Desa Nainggolan yang 3/4 areanya dikelilingi Danau Toba menjadikan desa ini memiliki potensi besar untuk dikembangkan menjadi tujuan wisata. Salah satu potensi utama dari desa ini adalah area tepi air yaitu Pantai Pasir Putih Pandua. Adapun pengembangan area tepi air pada Desa Nainggolan telah mulai diupayakan, namun dirasa belum optimal. Kurangnya fasilitas pendu kung kepariwisataan pada area tepi air menjadikan desa Nainggolan kurang dikenal dikalangan wisatawan yang berkunjung ke Pulau Samosir. Untuk itulah kajian mengenai perancangan are tepi air dalam mendukung Desa Nainggolan sebagai tujuan wisata perlu dilakukan. Penelitian mengenai perancangan area tepi air pada Desa Nainggolan dilakukan dengan prosedur kualitatif, informasi yang digunakan merupakan informasi hasil observasi lapangan serta kajian literartur. Penelitian ini terfokus pada perancangan area tepi air Desa Nainggolan yaitu Pantai Pasir Putih Pandua, agar dapat dimaksimalkan potensinya sebagai tujuan wisata
\end{abstract}

Kata Kunci: Area Tepi Air, Desa Nainggolan

\begin{abstract}
Nainggolan Village is one of the villages located on Samosir Island, North Sumatra Province. The existence of Samosir Island as one of the attractions in North Sumatra Province makes the entire area of the island has the potential for tourism development. The condition of Nainggolan Village which is 3/4 of its area surrounded by Lake Toba makes this village has great potential to be developed as a tourist destination. One that can become the main potential of this village is the waterfront area of Pantai Pasir Putih Pandua. The development of the waterfront area in Nainggolan Village has begun to be pursued, but is felt to be not yet optimal. The lack of tourism support facilities in the waterfront area makes Nainggolan village less well-known among tourists visiting Samosir Island. For this reason, a study of water edge design in supporting Nainggolan Village as a tourist destination needs to be done. Research on the design of the waterfront area in the Village Nainggolan conducted with qualitative methods, the data used are data from field observations and literary studies. This research is focused on designing the waterfront area of Nainggolan Village, Pantai Pasir Putih Pandua, so that its potential can be maximized as a tourist destination.
\end{abstract}

Keywords: Waterfront Area, Nainggolan Village

(C) 2020 The Authors. Published by TALENTA Publisher Universitas Sumatera Utara Selection and peer-review under responsibility of Seminar Nasional Kearifan Lokal V 2020 p-ISSN: 2654-7031, e-ISSN: 2654-704X, DOI: 10.32734/ee.v3i1.869 


\section{Pendahuluan}

Desa Nainggolan merupakan salah satu desa yang terletak di Kecamatan Nainggolan, Kabupaten Samosir, Provinsi Sumatera Utara, Indonesia. Desa dengan luas area sebesar 5,30 km2 ini terletak di bagian Tenggara Pulau Samosir. Selain area tepi air yaitu Pantai Pasir Putih Pandua, Desa Nainggolan juga memiliki potensi seperti pegunungan dan persawahan yang dapat menjadi pendukung potensi visual untuk diperhitungkan sebagai tujuan wisata Gambar 1.

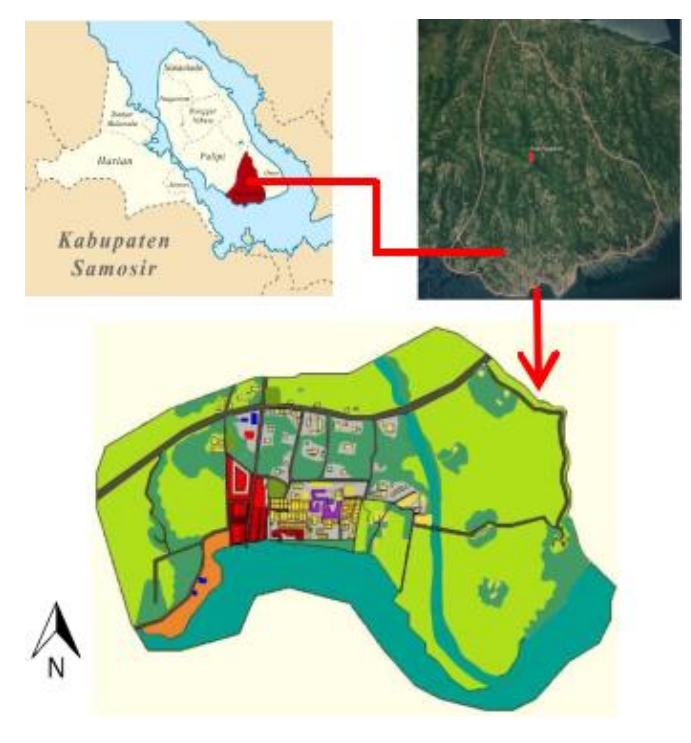

Gambar 1. Lokasi Desa Nainggolan

Menurut Badan Pusat Statistik Pulau Samosir tahun 2018, Desa Nainggolan adalah termasuk desa Swakarya, yaitu desa yang telah dapat memenuhi kebutuhannya sendiri dan dapat mulai memasarkan produksinya kedaerah-daerah lain dalam hal ini berupa hasil pertanian dan hasil ternak. Keterbukaan masyarakat serta sarana prasarana yang tergolong cukup baik dapat dikembangkan dan dijadikan faktor pendukung pengembangan sektor pariwista pada desa Nainggolan sehingga dapat menjadikan Desa Nainggolan sebagai desa wisata.

\section{Kajian Pustaka}

\subsection{Area Tepi Air}

Zona Tepi Air ataupun biasa disebut Waterfront ialah suatu peninggalan yang di miliki oleh sesuatu kota yang bisa dimanfaatkan buat kepentingan universal dengan bermacam tujuan seperti yang diungkapkan dalam harian“ prinsip perancangan kawasan tepi air'[7]. Konsep Waterfront bertujuan buat mendesak pemanfaatan ruang pesisir yang mempunyai nilai murah, nilai estetis, serta melindungi kelestarian area lewat pembangunan[5]. Pengelolaan zona tepi air ataupun waterfront merupakan hasil pembangunan yang mempunyai kontak visual serta raga dengan air serta ialah bagian dari upaya dalam pengembangan daerah perkotaan yang secara raga alamnya bersebelahan dengan air serta wujud pengembangannya berorientasi pada wilayah perairan[1], zona tersebut berbatasan dengan air yang dalam pengembangannya sanggup memasukkan nilai manusia, ialah kebutuhan hendak ruang publik serta nilai natural

[2]. Adapun prinsip yang diterapkan dalam pengembangan kawasan tepi air yang diungkapkan oleh L. Azeo Torre dalam bukunya Waterfront Development pada umumnya terdiri atas empat hal pokok yaitu konsep, aktivitas, tema dan fungsi yang dikembangkan[8]. Upaya berikut berkaitan dengan pengelolaan desa wisata tepi danau tidak hanya terfokus pada pengelolaan sekitar danau tersebut tetapi juga memperhatikan kawasan di sekitar danau. Pada PP No. 47 tahun 1997 tentang 
Rencana Tata Ruang Wilayah Nasional, disebutkan bahwa kawasan disekitar danau/waduk ditetapkan sebagai area yang termasuk dalam wilayah perlindungan tempatan.

Kriteria kawasan lindung untuk area disekitar danau juga ditetapkan dalam RTRW Nasional yaitu daratan sepanjang tepian danau/waduk yang proporsional dengan bentuk dan kondisi fisik danau/waduk antara 50-100 meter dari titik pasang tertinggi ke arah darat (PP No. 47 Tahun 1997, Pasal 34 Ayat 3). Pengaturan pengelolaan, pemanfaatan dan pengamanan waduk / danau menjadi dasar dalam usaha menjaga pemanfaatan dan pengelolaan danau/waduk dan tetap menjamin keberlanjutan dan kelestarian lingkungan di danau/waduk serta kawasan sekitarnya. Masa depan rekreasi tepi air terhubung dengan pengaturan kualitas sumber daya air, fasilitas, penyedia, infrastruktur yang dimiliki oleh masyarakat lokal dan perilaku terhadap wisatawan. Penentuan kualitas ini juga didasarkan pada pengalaman yang didapatkan oleh pengunjung dan wisatawan terhadap rekreasi air tersebut. Penentuan terhadap baiknya kualitas juga ditemukan oleh kualitas pengalaman rekreasi air yang diterima oleh wisatwan dan kelompok pemangku kepentingan.

\subsection{Perencanaan dan Perancangan Area Wisata Air}

Pembangunan zona wisata pada tepi air hendaknya dirancang bersumber pada kemampuan daya tarik yang berpedoman kepada kriteria keberhasilan pengembangan. Ada pula panduan tersebut meliputi bermacam kelayakan ialah, (1) Kelayakan Ekonomi yang berkaitan dengan perhitungan ekonomi pembangunan objek wisata. Perkiraan untung- rugi telah wajib diprediksi dari dini. Berapa lama waktu yang diperlukan buat balik modal pula telah diprediksi;(2) Kelayakan Sosial Ekonomi. Kelayakan ini dicoba untuk mengenali apakah investasi yang dikeluarkan buat membangun objek wisata bisa membagikan dampak sosial ekonomi secara regional; bisa menghasilkan lapangan pekerjaan, bisa tingkatkan penerimaan wilayah, bisa menaikkan penerimaan pada zona yang lain semacam pajak, perindustrian, perdagangan, pertanian. Dalam perihal ini pertimbangan tidak sekedar menimpa komersial saja namun pula mencermati akibatnya secara lebih luas;( 3 ) Kelayakan Teknis. Pembangunan objek wisata wajib bisa dipertanggungjawabkan secara teknis dengan memandang energi dukung yang terdapat. Daya tarik sesuatu objek wisata hendak menurun ataupun apalagi lenyap apabila objek wisata tersebut membahayakan keselamatan para turis;(4) Kelayakan Area. Analisis dampak area wisata bisa digunakan bagaikan acuan aktivitas pembangunan sesuatu objek wisata. Pembangunan objek wisata yang menyebabkan rusaknya area wajib dihentikan.[9].

Kriteria pengembangan zona wisata tepi air merupakan;( 1) Menggunakan keadaan raga pada tepi laut buat aktivitas tamasya,( 2) Pembangunan ditunjukan sejauh tubuh air dengan mempertahankan ruang terbuka,( 3) Menggunakan kekhasan arsitektur lokal bagaikan energi tarik,(4) Menggunakan keadaan raga tepi laut,[6]. Pembangunan prasarana wisata dengan mencermati keadaan posisi bisa meningkatkan aksesibilitas objek wisata serta akan tingkatkan energi tarik objek wisata itu sendiri. Di samping hal- hal di atas, kebutuhan penunjang perlu disediakan. Membangun prasarana wisata butuh koordinasi antara lembaga terpaut dengan lembaga pariwisata pada sebagian peringkat pemerintah. Sokongan lembaga terkait buat melengkapi prasarana wisata sangat dibutuhkan. Koordinasi pada sesi penerapan adalah aspek utama berhasilnya pembangunan pariwisata. Pemerintah berfungsi berarti dalam pembangunan prasarana pariwisata karenadapat mengambil keuntungan ganda, ialah buat tingkatkan arus data, arus kemudian lintas ekonomi, arus mobilitas manusia antara wilayah, serta sebagainya, serta bisa tingkatkan peluang berupaya serta bekerja untuk warga[3].

\subsection{Pengelolaan Area Wisata Tepi Air}

Dalam pengelolaan kawasan Wisata Tepi Air disusun metoda pengelolaan yang di jalankan di Indonesia ialah kerjasama antara Pemerintah serta Swasta ataupun BOT( Built OperationTransfer). Metoda ini mengaitkan swasta dalam pembangunan sarana publik, tanggung jawab serta keberadaan swasta terus menjadi besar. Sistem kontrak yang dilaksanakan berlaku sesuai kesepakatan. Sepanjang waktu tersebut swasta melaksanakan pembangunan, pengelolaan, pengoperasian, pendayagunaan, serta pengambilan keuntungan. Pemerintah membantu swasta dalam memfasilitasi serta menyediakan tim monitoring, hingga masa kontrak berakhir serta kawasan wisata jadi peninggalan pemerintah seutuhnya[4]. Tahapan dalam sistem pengelolaan BOT ialah:( 1) Sesi Persiapan, yang berisi pengaturan hak serta kewajiban oleh tiap- tiap pihak;( 2) Proses penerapan Kerjasama;( 3) Sesi Pembangunan( 4) Sesi Pengelolaan, dimana 
swasta pula mengajak pihak ketiga semacam orang dagang, pekerja, lembaga peminjaman dana serta lain- lain;( 5) Sesi Penyerahan Kembali, yang diawali dengan peralihan operasional kepada pemerintah. Pada masa ini pemerintah melaksanakan pelatihan pekerja biar menjajaki aturan- aturan operasional baru yang diterapkan. Pada sesi pengelolaan ini dana yang dipakai merupakan memakai dana pemerintah.

\section{Metodologi}

Penelitian dilakukan pada Desa Nainggolan, Kabupaten Samosir, Provinsi Sumatera Utara. Hasil observasi pada kondisi area tepi air Desa Nainggolan dianalisa dengan studi literatur. Adapun data sekunder diperoleh melalui instansi pemerintah setempat yang menghasilkan data mengenai kegiatan sosial budaya, ekonomi serta upaya pengembangan yang belum optimal pada kawasan tepi air sehingga menghasilkan potensi dan solusi perancangan area tepi air pada Desa Nainggolan. Perancangan ini dikaji dalam konteks pengembangan area tepi air dalam mendukung desa Nainggolan sebagai tujuan wisata. Adapun metode penelitian yang digunakan adalah metode kualitatif untuk mendeskripsikan permasalahan dan potensi apa saja yang dimiliki kawasan tepi air Desa Nainggolan serta digunakan untuk menganalisis perancangan kawasan yang tepat untuk kawasan Pantai Pasir Putih Pandua agar dapat menjadi daya tarik wisata pada Desa nainggolan.

\section{Pembahasan}

Desa Nainggolan adalah salah satu desa yang terletak di Kecamatan Nainggolan, Kabupaten Samosir, Provinsi Sumatera Utara, Indonesia. Desa Nainggolan berbatasan dengan Desa parhusip III sebagai batas di sebelah utara, desa Sibonor Ompu Ratus dan desa Sinaga Uruk Pandiangan disebelah barat. Kemudian pada bagian selatan, Desa Nainggolan berbatasan dengan Danau Toba, dan bagian Timur berbatasan dengan desa Siruma Hombar dan desa Sipinang Lumban Siantar.

Ditinjau dari aspek area tepi air, potensi alam berupa danau dapat dijadikan nilai tambah untuk dikembangkan menjadi desa wisata. Keberadaan danau Toba memberikan daya tarik tersendiri bagi desa Nainggolan untuk berkunjung. Berdasarkan dari hasil tinjauan kelapangan, lokasi pinggiran danau Toba secara perlahan dikembangkan oleh pihak pemerintah setempat. Daerah pinggiran danau tersebut difungsikan untuk rekreasi air dan menjadi daerah pemberhantian kapal-kapal yang akan menyebrang dan datang. Namun upaya pengembangan ini dirasa belum maksimal karena tidak dibarengi penambahan fungsi komersil dan fasilitas pendukung bagi area wisata Gambar 2.

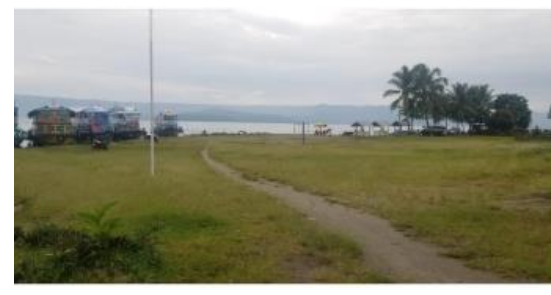

(a) Ruang Terbuka di Pantai Pasir Putih Pandua

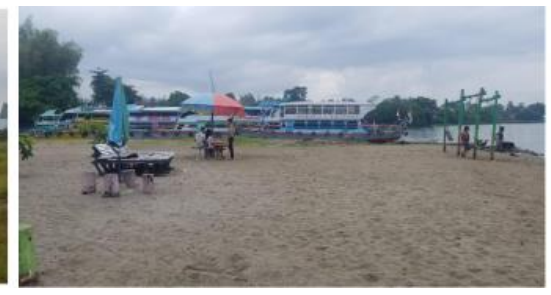

(b) Pantai Pasir Putih Pandua

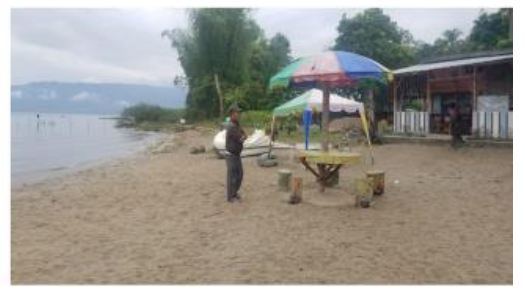

(c) Fasilitas di Pantai Pasir Putih Pandua 
Dapat dilihat pada gambar dibawah, Danau Toba mengelilingi 3/4 dari desa Nainggolan hingga menjadikan desa ini mempunyai potensi alam yang sangat baik untuk dikembangkan menjadi tujuan wisata tepi air Gambar 3.

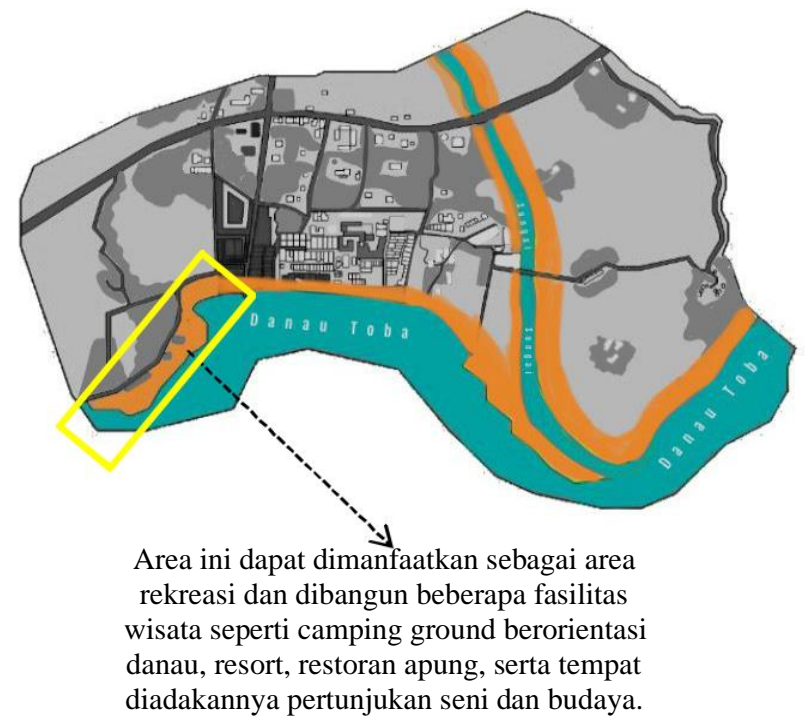

Gambar 3. Analisa Potensi Area Tepi Air Desa Nainggolan

Berikut adalah analisa Permasalahan dan Solusi dari Area Tepi Air Pantai Pasir Putih Pandua Desa Nainggolan, Gambar 4.

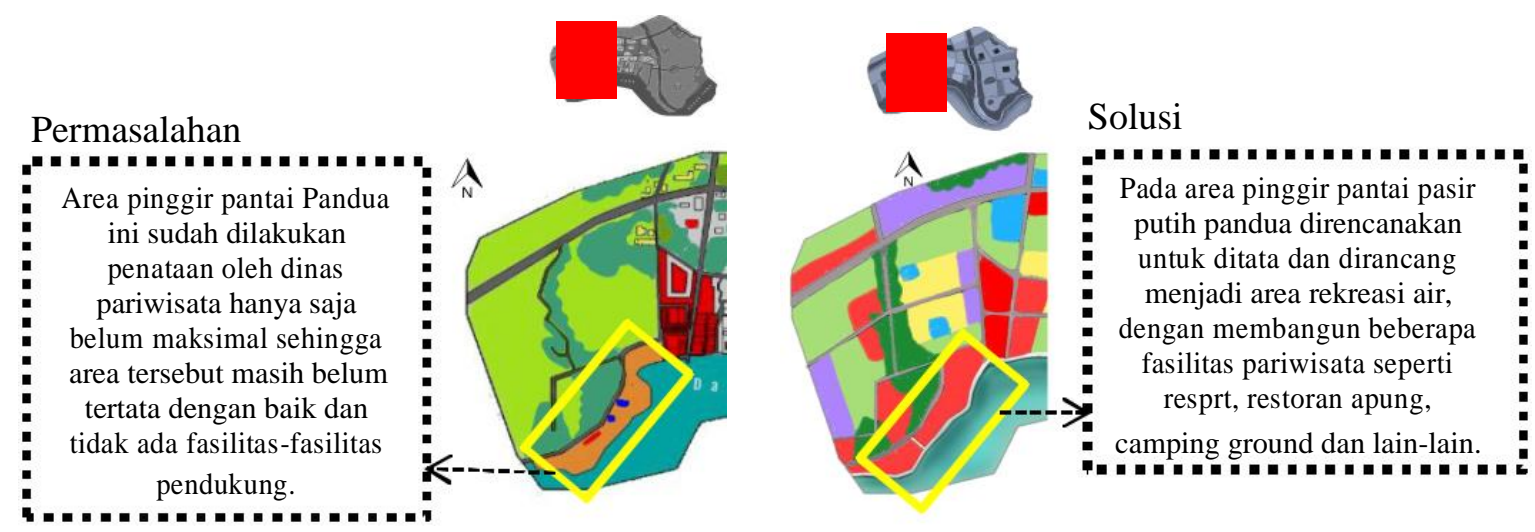

Gambar 4. Analisa Permasalah dan Solusi pada Pantai Pasir Putih Pandua Desa Nainggolan

Desa Nainggolan memiliki potensi alam berupa danau. Area tepi air tersebut dapat ditata dan dikembangkan fungsinya sebagai urutan visual dan tempat untuk rekreasi, dengan dibangunnya beberapa fasilitas wisata seperti resort, restoran terapung, tempat pertunjukan seni dan budaya, serta camping ground berorientasi danau, Gambar 5 .

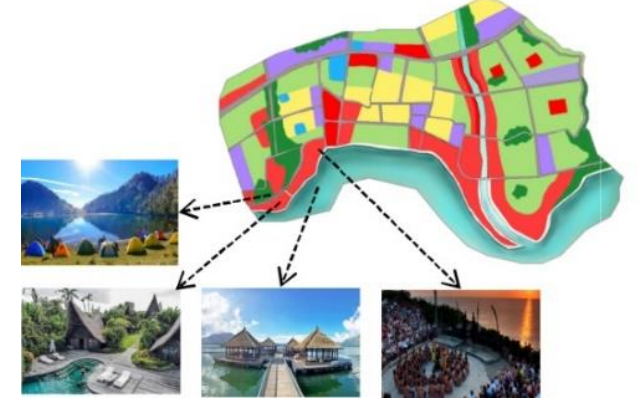

Gambar 5. Konsep Perancangan Area Tepi Air Pantai Pasir Putih Pandua Desa Nainggolan 


\section{Kesimpulan}

Melalui Observasi yang dilakukan terhadap area tepi air Desa Nainggolan, diketahui bahwa kawasan tepi air Pantai Pasir Putih Pandua mempunyai potensi visual yang dapat dikembangkan menjadi tujuan wisata di Desa Nainggolan, adapun upaya pengembangan yang telah mulai dilakukan pihak dinas pariwisata dapat dikatakan belum optimal. Dengan penelitian mengenai Perancangan Area Tepi Air ini diharapkan dapat menjadi pedoman bagi pemerintah dalam mengembangkan potensi Desa Nainggolan khususnya area tepi air desa nainggolan, Pantai Pasir Putih Pandua sebagai tujuan wisata di Pulau Samosir.

\section{Referensi}

[1] Breen, A., \& Rigby, D. (1994). Waterfronts: Cities reclaim their edge. McGraw-Hill Companies.

[2] Carr, S., Stephen, C., Francis, M., Rivlin, L. G., \& Stone, A. M. (1992). Public space. Cambridge University Press.

[3] Dewi, M. H. U. (2013). Pengembangan desa wisata berbasis partisipasimasyarakat lokal di Desa Wisata Jatiluwih Tabanan, Bali. JurnalKawistara, 3(2).

[4] Farhani \& Sunaryo.(2014). Konsepsi Pengelolaan Berkelanjutan Pasar Apung Banjir Kanal Barat Kota Semarang. Jurnal ruang. 2

[5] Mahadi, K., \& Indrawati, F. (2010). Arahan Pengembangan Obyek Wisata Pantai Tanjung Pasir Kabupaten Tangerang. Jurnal PLANESATMVol, l(1).

[6] Ridwan, M. (2010). ARAHAN PENATAAN KAWASAN TEPI AIR (WATERFRONT) SUNGAI MUSI SEBAGAI PENGEMBANGANKAWASAN PARIWISATA (Doctoral dissertation, Fakultas Teknik Unpas)..

Sastrawati, I. (2003). Prinsip perancangan kawasan tepi air (kasus: kawasan Tanjung Bunga). Journal of Regional and City Planning, 14(3), 95-117.

[7] Sastrawati, I. (2003). Prinsip perancangan kawasan tepi air (kasus: kawasan Tanjung Bunga). Journal of Regional and City Planning, 14(3), 95-117.

[8] Torre, L. A. (1989). Waterfront development. Van Nostrand Reinhold.

[9] Zebua, C. A. P. (2018). Strategi pengembangan kepariwisataan kabupaten nias dalam upaya menunjang pendapatan asli daerah (studi kasus di dinas pariwisata kabupaten nias) 